\title{
O SUDESTE ASIÁtico E O ÍNDICO: REFLEXões SOBRE TRÂNSITOS LINGUÍSTICOS E TRAVESSIAS CULTURAIS NAS TRADIÇÕES ORAIS EM TIMOR- -LESTE
}

\author{
Aone van Engelenhoven ${ }^{1}$ \\ Kamila Krakowska Rodrigues ${ }^{2}$
}

\begin{abstract}
Resumo: Apesar de o Sudeste Asiático dever algumas religiões, sistemas de escrita, elementos de mitologia e vocabulário aos contactos interculturais estabelecidos no Índico, essa região tem recebido muito pouca atenção no campo dos Estudos do Índico (REID, 2007). Tendo em vista a necessidade de preencher tal lacuna e com o fim de oferecer uma melhor compreensão da geografia cultural e identitária do Índico como um espaço transnacional, este texto propõe analisar as tradições orais em Timor-Leste como uma ferramenta metodológica para estudar a memória (e o esquecimento) dos trânsitos culturais que influenciaram a formação desse país de língua oficial portuguesa. A análise das narrativas orais provenientes do Timor-Leste e das vizinhas Molucas Ocidentais revela como as categorias operacionais "língua" e "nação" se tornam problemáticas em contextos transnacionais como o do Índico. Diante da presença portuguesa nesses mares, as tradições orais confrontam os pesquisadores com problemas e desafios de ordem metodológica que questionam universalismos construídos a partir de fatores histórica e politicamente determinados.
\end{abstract}

Palavras-chave: Timor-Leste; Índico; tradições orais.

O mundo nasce no leste e vai crescendo com a passagem do sol pelo horizonte. Os povos do leste são os mais velhos e os mais sábios. No entanto, num passado bem antigo, os antepassados cometem um pecado

1 Assistant Professor, Leiden University Center for Linguistics, Leiden University, Netherlands: a.van.engelenhoven@hum.leidenuniv.nl.

2 Assistant Professor, Leiden University Center for the Arts in Society, Leiden University, Netherlands: k.k.krakowska.rodrigues@hum.leidenuniv.nl. 
que deixa os mais velhos vulneráveis às astúcias dos seus irmãos mais jovens. Assim, os jovens que chegam pelo mar do ocidente conseguem vencer o povo da terra dos nascer do sol. ${ }^{3}$

Essa crença, relatada aqui no presente para representar a ambiguidade temporal das línguas austronésias, chama a atenção para a importância do Índico para a história e a cultura do Sudeste Asiático. De facto, como aponta Anthony Reid (2007, p. 100), essa região deve algumas religiões, sistemas de escrita, elementos de mitologia e vocabulário aos contactos interculturais estabelecidos no Índico, o primeiro oceano a ser navegado (PEARSON, 2003, p. 3). No entanto, como adverte Reid (2007), o Sudeste Asiático tem recebido muito pouca atenção no campo dos Estudos do Índico. O historiador aponta para fatores de caráter económico e político, bem como para uma necessidade de autonomia e delimitação do campo de estudo por parte das disciplinas (relativamente) emergentes, como é o caso de Estudos do Sudeste Asiático, para explicar esse fenómeno. Tendo em vista a necessidade de preencher tal lacuna e com o fim de oferecer uma melhor compreensão da geografia cultural e identitária do Índico como um espaço transnacional, este texto propõe analisar as tradições orais em Timor-Leste como uma ferramenta metodológica para estudar a memória (e o esquecimento) dos trânsitos culturais que influenciaram a formação desse país de língua oficial portuguesa.

A tradição oral, no contexto do Sudeste Asiático, é um elemento imprescindível no mapeamento da expressão cultural dos seus povos. A oralidade desempenha nessa região um papel crítico como receptáculo da memória cultural e do conhecimento histórico. Como salientam Engelenhoven e Nazarudin (2016), as narrativas orais frequentemente são o único material acessível para interpretar história, devido à inexistência ou inacessibilidade de fontes escritas e artefactos arqueológicos. Essa perspectiva é congruente com o trabalho inovador de Jan Vansina (1985), no contexto africano no qual o historiador belga defendeu a relevância das tradições orais como fontes de pesquisa histórica. As metodologias tradicionais de pesquisa histórica são baseadas em textos escritos e descrições orais dos intervenientes em eventos históricos recentes (a chamada história oral). O tipo de dados tratados no presente artigo (tradição oral) não substitui mas complementa essas metodologias.

3 Explicação dada por um velho Makuva, em Porlamano, durante o trabalho de campo do Maku’a Pilot Project (2003, financiado por Hans Rausing Endangered Languages Programme). 
No âmbito da tradição-oral-como-história, diversas fontes - incluindo narrativas épicas, cantigas, provérbios, ou lendas -, oferecem informções sobre mentalidades, valores e normas éticas inscritos na sociedade, crenças, costumes, mas também sobre o impacto de eventos históricos marcantes para o imaginário local (VANSINA, 1985).

A recolha e o estudo das narrativas orais na zona do Sudeste Asiático, como argumentaremos, permite mapear a formação das identidades num contexto transnacional que, como salienta Isabel Hofmeyr (2010, p. 722), "complicates binarisms, moving us away from the simplicities of the resistant local and the dominating global and toward a historically deep archive of competing universalisms". ${ }^{4}$ Como é que a chegada dos colonizadores europeus é recordada na memória popular? Quais são (e como são contadas) as narrativas que circulam sobre a luta pela independência? Como são representadas as diferentes etnias vizinhas e as suas interações? Qual é a ligação emotiva e simbólica dos povos com os espaços local, nacional e transnacional? As tradições orais são, nesse sentido, uma fonte fundamental para a melhor compreensão dos processos de formação de comunidades e da sua (re)imaginação.

No caso de Timor-Leste, Aone van Engelenhoven (2013) desenvolveu um extenso trabalho de análise da topologia narrativa dos contos orais, identificandoaimportânciadousodosnomes, quefuncionamcomoclichés, dos artefactos visuais, por exemplo espaços naturais emblemáticos, e das canções que acompanham as narrativas. Outros estudos demonstram a influência da tradição oral como modelo narratológico sobre outras formas de literatura, nomeadamente poesia contemporânea e, especialmente, escrita em prosa (MOUTINHO, 2012). Segundo argumenta a autora, o estilo da escrita por autores da diáspora timorense, como Luís Cardoso, Ponte Pedrinha e Domingos de Sousa, é marcado pela "combination of a strong concern with historicity with various, and distinctive, styles of storytelling" (p. 103). ${ }^{5}$ Numa perspectiva diversa, Nuno Gomes da Silva (2007) analisa diferentes géneros presentes na tradição oral timorense, identificando os códigos culturais neles transmitidos de geração em

\footnotetext{
4 "[...] complica os binarismos, afastando-nos das simplicidades do local resistente e do global dominante e aproximando-nos para um arquivo historicamente rico de universalismos em competição".

5 "[...] combinação duma forte preocupação com a historicidade com variados e característicos estilos narrativos”.
} 
geração, e reflete sobre como esse material pode ser usado para o ensino da língua portuguesa no sistema escolar timorense.

A tradição oral revela-se também crucial na criação de um imaginário nacional. Vicente Paulino (2016) argumenta que a criação de identidade cultural após um conflito que afetou os laços comunitários passa pela preservação do património cultural e, no caso de Timor-Leste, o académico identifica os artefactos materiais com motivos mitológicos (por exemplo cerâmica, armas, estátuas) como simbolizantes de uma escrita figurativa e fundamentais para despertar um sentido de inclusão e respeito mútuo entre várias comunidades dentro da nova nação timorense. No entanto, na nossa opinião esses objectos apenas ganham o seu significado simbólico quando relacionados com as respectivas narrativas orais. A comunicação visual, nesse contexto, é um artefacto narrativo, ponto de partida para o ato de contar, que não pode funcionar independentemente.

No entanto, não existe nenhum estudo que discuta o repensar dos trânsitos transnacionais na zona do Índico e do seu impacto cultural nas tradições orais do Sudeste Asiático. O presente artigo baseia-se em dados recolhidos por Aone van Engelenhoven durante a sua pesquisa em Timor-Leste e na Indonésia e, de forma exploratória, traça algumas linhas temáticas que poderão ser desenvolvidas de forma mais sistemática no futuro, com o recurso a trabalho de campo e recolha de narrativas. Mais fundamentalmente, como argumentaremos, o estudo de tradição oral coloca uma série de questões metodológicas específicas desse campo de estudo que se revelam muito pertinentes para a conceptualização do estudo das geografias culturais de carácter transnacional, como é o caso do Oceano Índico.

\section{A(S) LÍNGUA(S)}

A primeira questão com que um estudioso das literaturas orais é confrontado é a questão da língua. Em que língua conduzir as entrevistas? Que versões gravar, transcrever e eventualmente traduzir? O trabalho pioneiro de Ruth Finnegan (1992) demonstra como é crucial entender a tradição oral como uma prática cultural multidimensional, que envolve tanto o texto - a narrativa em si - como a sua "performance". Cada vez que o texto é encenado, somos confrontados com um "original” novo (FINNEGAN, 1992). Assistir a um ato de contar na língua que é habitualmente usada pela comunidade para a sua partilha e transmissão 
permite uma melhor contextualização da narrativa e uma aproximação aos códigos culturais, que podem ser perdidos no processo de tradução.

Alguns investigadores optam por recolher as narrativas orais timorenses em português, como éo caso das colectâneas de contos editadas por Anabela Leal de Barros (2015, 2017), que pretendeu estudar a maneira como o português é usado em Timor-Leste, além de divulgar o imaginário cultural timorense. No entanto, a maior parte dos investigadores que trabalham sobre a oralidade no Sudeste Asiático (por exemplo, Nuno Gomes da Silva e Aone van Engelenhoven) e em outras regiões do mundo (eg., Chao Gejin no contexto de Ásia Central, Dennis Tedlock no contexto de América do Sul e Daniela Merolla no contexto da África do Norte) reconhecem a necessidade de aceder ao texto/performance na língua indígena. No entanto, essa alternativa também coloca questões de ordem metodológica. “Quem é que ainda fala a língua indígena?” parece uma pergunta controversa, ou até provocatória, mas é uma questão que tem de ser abordada com rigor para evitar possíveis falhas de comunicação (e interpretação). Frequentemente o público local presume que entende o conteúdo da narrativa, mas de facto os participantes mais novos podem não ter competências linguísticas suficientes para acompanhar todos os detalhes das narrativas construídas com o uso de formas gramaticais antigas e expressões arcaicas.

"O que ele diz?" - pergunta o investigador.

"Deixe o velho falar" - responde o jovem informante.

Esse diálogo é frequementemente interpretado como uma expressão de respeito devido aos mais velhos na comunidade, sem averiguar a razão/ as razões. Há também outras explicações, se calhar não exclusivas, mas certamente complementares. $\mathrm{O}$ ato de contar cria um tempo-espaço de sabedoria, e interromper a história implica uma perda. Essa convenção social resulta na relutância do público em questionar o contador e pedir explicações.

Qual é a relevância dessas reflexões para o estudo das narrativas transnacionais do Oceano Índico em geral e do Índico Lusófono em particular? As zonas de contacto transnacionais são caracterizadas pela emergência de várias estratégias de comunicação, pelo estabelecimento de línguas francas e/ou pelos processos de creolização. Se pretendemos estudar a memória cultural dos trânsitos culturais que foram alterados e/ou renegociados pela chegada dos portugueses ao Índico e à sua 
intromissão na existente rede de contactos comerciais, que narrativas devem ser consideradas no corpus? O foco nos espaços que estiveram sob o domínio português durante tempo suficiente parapermitir criar dinâmicas culturais próprias em língua portuguesa (o caso de Goa), ou nos países que pertencem à Comunidade dos Países da Língua Portuguesa (o caso de Moçambique e Timor-Leste) parece uma solução racional e lógica (embora suscetível de crítica, como discutiremos adiante). No entanto, nesses países/territórios existe material de pesquisa produzido em outras línguas que não o português. Como delimitar o corpus de uma maneira sistemática e bem fundamentada?

Na nossa opinião, para captar as dinâmicas transnacionais dos contactos (inter)culturais no Índico, a análise não pode cingir-se apenas nas narrativas produzidas em português. $\mathrm{O}$ carácter multilíngue desse tipo de espaço exige também uma abordagem multilíngue, o que é especialmente relevante no caso de Timor-Leste. Incluir as narrativas produzidas em português, tetum, mambai, makasae, ou fataluco, para enumerar apenas algumas das línguas usadas no país, permitirá um mapeamento mais inclusivo das travessias e da memória cultural do Índico. A escolha da língua por parte do narrador/contador é em si um ato de expressão cultural e identitária. Uma pesquisa focada nas tradições orais transmitidas em Timor-Leste no contexto do Índico "lusófono" permitirá deslocalizar o próprio conceito de lusofonia como apenas um dos possíveis agrupamentos no estudo de literaturas e culturas marcadas pela história colonial portuguesa, e traçar "outras geografias do saber", que Jessica Falconi (2012) observa na literatura moçambicana virada para o Îndico. Essas geografias alternativas "poderão talvez configurar novos territórios e novas formas de resistência, a partir das muitas geografias traçadas pelas narrativas da nação pós-colonial, que, ao convocarem outras margens e fronteiras, outras matrizes, outras histórias acabam por desarticular também o imaginário da lusofonia" (FALCONI, 2012, p. 287).

De facto, o estatuto do português em Timor-Leste está vinculado a relações de poder e hierarquias estabelecidas em vários momentos críticos da história timorense. Os timorenses apreciam o conhecimento de várias línguas; budi bahasa (que pode ser traduzido como "mestria de língua"), por exemplo, define a atitude local perante o multilinguismo. Atualmente, em Timor-Leste o português e o tetum têm o estatuto de línguas oficiais, e, de acordo com o censo de 2004, eram faladas por $36 \%$ e $86 \%$ da população (cf. TAYLOR-LEECH, 2008). No mesmo censo, 59\% 
das pessoas declarou fluência no indonésio, a língua oficial no período da ocupação de 1975-200o. Além das (atuais e antigas) línguas oficiais, o censo distingue 32 variantes linguísticas endógenas, entre as quais o tetum, com o maior número de falantes. ${ }^{6}$ No entanto, como advertem Goglio e Afonso (2012), diferentes gerações dominam de forma distinta as diferentes línguas que funcionam no país independente. Goglia e Afonso (2012, p. 78) assim resumem a diglóssia existente:

As for the relationship between the languages, there has always been a situation of diglossia [...] with asymmetrical multilingualism, imposed by the linguistic history of the country, in which Portuguese is the High language, Tetum is progressively being used in High domains, at the same time as it coexists in Low domains. The national languages are the Low languages, English and Bahasa Indonesia compete with the official languages, and Bahasa Indonesia is still widely used both as a High language and in lower domains. ${ }^{7}$

O português não é apenas uma língua de estatuto social elevado, derivado de sua associação com a literacia e o conhecimento científico, mas é também um meio de recriação simbólica da identidade nacional. Ao nível da política linguística do país, o português vem substituir o indonésio, que tinha estatuto elevado durante a ocupação. A consciência de diferentes níveis de prestígio associado e diferentes expectativas frente a uma língua nacional levou o Fretilim a propor a língua portuguesa como a língua oficial do Timor-Leste independente. A ausência duma literatura escrita e dum vocabulário científico causou, inicialmente, a desvalorização do tetum como um candidato sério para a língua oficial. Por causa dos sentimentos negativos e protestos na sociedade, depois da independência o tetum - sendo mais conhecido que o português - foi proposto como a língua co-oficial da nação. Paralelamente, cada língua regional - não só as línguas com muitos falantes como o mambai, mas também uma língua quase extinta como o macuva - foi reconhecida pelo Instituto Nacional de Linguística e recebeu o estatuto de língua nacional. Simbolicamente,

\footnotetext{
6 A variante de tetum escolhida para estandardização e escolarização é a falada na capital, ou seja, tetum-praça ou tetum-Díli, sendo que as outras variantes dominam na zona sul e no ocidente do país.

7 "Relativamente à relação entre as línguas, houve sempre uma situação de diglossia [...] com multilinguismo assimétrico imposto pela história linguística do país, em que o português é a língua alta, o tetum é progressivamente mais usado num contexto elevado, enquanto coexiste em contextos baixos. As línguas nacionais são as línguas baixas, o inglês e o indonésio competem com as línguas oficiais, e o indonésio ainda é amplamente utilizado tanto como língua alta como em contextos baixos.”
} 
essas línguas indígenas são uma via de transmissão de conhecimentos tradicionais, conectando o falante com o passado histórico e mítico.

Em 2014, Engelenhoven introduziu o termo "folclore linguístico" para designar as opiniões sobre uma língua que circulam em forma oral numa dada comunidade e, em 2017, especificou o "folclore linguístico" como as opiniões sobre uma língua não conhecida em contraste com a ideologia linguística que se refere a opiniões sobre uma língua conhecida. Nesse sentido, o folclore linguístico implica o surgimento de narrativas sobre uma língua cujo conhencimento seja encapsulado apenas em palavras soltas, sem possibilidade de comunicar-se fluentemente por meio dela. No caso de Timor-Leste existe um conflito entre o folclore linguístico que envolve o português - conhecido por um pequeno segmento da sociedade leste-timorense - e a ideologia linguística do tetum, que é a língua indígena mais conhecida nessa sociedade. No pensamento dessa populção, o conhecimento do português - a língua do antigo colonizador com uma longa história literária - tornaria possível o acesso ao progresso que foi prevenido pela ocupação indonésia. $O$ português representa para eles a porta da modernidade e todas as vantagens económicas e científicas que não estão associadas às línguas indígenas.

Então, a "lusofonia" é interpretada como uma possibilidade de a nova nação fugir da imagem de subordinação e ignorância imposta pelos invasores nos vários momentos da história timorense. Curiosamente, essa imagem é conscientemente lembrada em relação ao período indonésio, mas esquecida em relação ao período de colonização portuguesa. Além de políticas linguísticas implementadas pelo governo com o fim de fomentar a identidade nacional como parte do imaginário transnacional lusófono, há outros mecanismos de (re)criação de mitos fundacionais da nação. Nomeadamente, os textos portugueses da época colonial sobre Timor são fonte para uma confirmação simbólica de sua pertença lusófona na atualidade. Desse modo, esses documentos de cariz histórico e antropológico tornam-se artefactos que sustentam narrativas (orais) de origem.

\section{A NAÇÃO}

Enquanto a língua se torna um critério de seleção problemático na delimitação do corpus de pesquisa no contexto transnacional do Sudeste Asiático, a nação como critério operacional também não é livre de 
questões de ordem metodológica. Estudar as narrativas orais emergentes apenas no território de Timor-Leste implica uma limitação de vozes, de perspectivas, de protagonistas, de artefactos que possivelmente possam contribuir para uma melhor compreensão dos trânsitos culturais do/no Índico. Essas escolhas podem ser necessárias devido à impossibilidade física e temporal de recolher um material tão vasto para a análise, no entanto achamos que é fundamental salientar que a memória dos fluxos interculturais e das travessias índicas no contexto lusófono não é narrada apenas em Timor-Leste, mas em várias partes do Sudeste Asiático.

Essa constatação parece óbvia, mas implica uma redefinição do foco de pesquisa de um espaço nacional para um espaço transnacional. Curiosamente, as relações transnacionais que aqui propomos estudar à primeira vista não parecem enquadrar-se na definição convencional do transnacionalismo como

\begin{abstract}
a condition in which, despite great distances and notwithstanding the presence of international borders (and all the laws, regulations and national narratives they represent), certain kinds of relationships have been globally intensified and now take place paradoxically in a planet-spanning yet common - however virtual - arena of activity. (VERTOVEC, 1999, p. 447) ${ }^{8}$

As tradições orais como fonte de informação histórica transmitem narrativas fundacionais das identidades que frequentemente precedem a formação dos estados-nação, representando transnacionalismo entendido como redes de contacto de longa distância, e não como mecanismos de globalização recentes (VERTOVEC, 1999, p. 447). No entanto, como argumentaremos, as narrativas orais "índicas" do Sudeste Asiático revelam a matriz transnacional do seu imaginário nessas duas vertentes: ora como memória cultural das seculares travessias índicas, ${ }^{9}$ ora como renegociação das identidades descentradas, tão próprias da época contemporânea, onde a(s) língua(s) e a(s) narrativa(s) constituem "a reality that invests us with the imperative to re-consider and re-view the very terms of aesthetic and ethical sense; that is, to rethink the very conditions of 'reality'". (CHAMBERS, 2014, p. 9) ${ }^{10}$
\end{abstract}

8 "[...] uma condição em que, apesar das grandes distâncias e da presença de fronteiras internacionais (e todas as leis, regulações e narrativas nacionais que elas representam), certos tipos de relações têm sido globalmente intensificadas e, paradoxalmente, têm agora lugar numa arena de actividade que cobre o planeta e é, no entanto, comum - apesar de virtual".

9 Sendo esta pesquisa desenvolvida no âmbito do projecto NILUS - Narrativas do Oceano Î́ndico no Espaço Lusófono (CESA/ISEG, Universidade de Lisboa, financiado pela FCT ref. PTDC/CPCELT/4868/2014), o nosso enfoque é no contexto lusófono.

10 "[...] uma realidade que nos impõe o imperativo de reconsiderar e rever os próprios termos do sentido estético e ético; isto é, repensar as próprias condições da 'realidade”". 
Precisamente, a tradição oral do Sudeste Asiático revela padrões de semelhança na estruturação das narrativas e só uma análise regional, ou até transregional, permitirá captar a complexidade e riqueza do seu imaginário cultural. Recorrendo ao trabalho seminal de Sweeney (1987), que observou serem as narrativas orais malaias construídas a partir de "pedaços narrativos", pequenos núcleos significativos que podem ser combinados de várias maneiras para construir histórias diferentes, Engelenhoven $(2010,2012)$ estudou a topologia narrativa dos contos do sudeste das Molucas e do leste timorense. Essa investigacão mostrou que as tradições orais da região - conhecida como Nuspaikra-Rapiatatra e caracterizada por uma rede de comércio local em que cada ilha se especializava num produto particular - são estruturadas de maneiras comparáveis. Cada história inclui pequenos elementos narrativos que confirmam a sua "veracidade", nomeadamente nomes das personagens e dos lugares emblemáticos, artefactos materiais e canções. Uma análise focada no espaço que ultrapassa as fronteiras nacionais é fundamental não só para captar as formas de narratologia oral como uma forma de expressão cultural e identitária, mas também para mapear a memória do transnacionalismo índico.

Um exemplo claro da importância do alargamento do corpus no estudo do Índico "lusófono" é o conto do kris dourado de Kisar. Kisar é uma pequena ilha pertencente ao distrito das Molucas, da República da Indonésia, localizada perto de Timor-Leste, que se distingue das outras ilhas vizinhas do ponto de vista topográfico e linguístico. Como relatado em Engelenhoven e Nazarudin (2016), a população divide-se em dois grupos etno-linguísticos que partilham as mesmas práticas culturais. A maioria Meher, falante de dialectos classificados como pertencentes ao grupo timorense das línguas austronésias, partilha a topologia linguística e as tradições locais com a maioria das ilhas vizinhas. A minoria woirata é falante de woirata, uma língua não austronésia, relacionada com a língua fataluco do distrito Laútem de Timor-Leste. Os dois grupos comunicamse ou numa variante local de malaio, ou em indonésio, e esse "apartheid linguístico" (ENGELENHOVEN; NAZARUDIN, 2016) é reforçado por mitos orais transmitidos tanto na comunidade woirata, como na meher."

A ilha ganha importância na historiografia colonial apenas em 1665, quando o capitão holandês Jan Blinne (ou Blime) assina um acordo que

11 Veja-se Engelenhoven e Nazarudin (2016) em relação às diferentes explicações míticas desse fenómeno. 
estabelecea inclusão da ilha na Companhia Holandesa das Índias Orientais e legitima, aos olhos dos holandeses, o poder do chefe local Cornelis Pakar como "rei" da ilha. Os estudos históricos existentes são muito escassos, mas as monografias novecentistas de cariz etnográfico de autoria de Riedel (1886) e de Reinwardt e Vriese (1858), e, já no século vinte, de Rodenwaldt (1928), oferecem uma visão geral sobre as interações das populações locais com as autoridades holandesas e do impacto da presença holandesa e da adesão à VOC (Vereenigde Oostindische Compagnie - companhia holandesa das índias orientais) para a identidade das várias comunidades que habitavam a ilha. Uma das marcas atualmente visíveis do processo de creolização que se seguiu na ilha é a proliferação dos nomes de origem holandesa. Segundo as narrativas orais que continuam a ser contadas por várias etnias locais, a chegada dos holandeses à ilha, que parece ser um acontecimento histórico incontornável na construção da sua memória cultural, foi provocada por um conflito com os portugueses.

Um dia cinco homens da Ilha Kisar, entre eles irmãos Pakar Norimarna e Pooroe e dois homens da aldeia Abusur, do clã Enitutun ou Nakar Dau, navegam a Timor Português [...] Quando chegam à praia Walu, encontram um português chamado Risanpuna. É sabido que o português tem muitas coisas valiosas e, entre elas, um kris cujo cabo e lâmina eram feitas de ouro. Os dois homens de Abusur desejam o kris e matam Risanpuna para consegui-lo. Este confronto obriga-os a regressar directamente para Kisar. (SAHUSILAWANE, 2008, p. 35$39)^{12}$

Esse é apenas um "pedaço narrativo" de várias histórias contadas por várias etnias que narram a origem do kris de Risanpuna, um símbolo do poder dos reis de Kisar, guardado na casa do clã Hihileli Halono. De ponto de vista de formação de identidade cultural e preservação da memória cultural, esse microconto ilustra que as identidades nesse território ilhéu, afetado por várias ondas de migrações, chegadas e partidas, não são identidades fixas e enraizadas no "chão", no território habitado e simbolicamente construído, mas são identidades fluidas e construídas "em relação", recorrendo à ideia de Glissant (2010) de identidades rizomáticas. De facto, a viajem a Timor é empreendida por membros de clãs diferentes, destacando que a identidade de um clã é formada num processo de renegociação entre o Eu e o Outro. Além disso, o símbolo do poder local provém não de Kisar, mas de uma ilha vizinha, o que parece salientar a importância dos trânsitos económicos,

12 Versão recolhida entre os hihileli (ou seus aliados) e publicada por Sahusilawane (2008, pp. 35-39). 
mas também culturais no Sudeste Asiático. Finalmente, o português, o estrangeiro vindo do além mar, é chamado com um nome de origem não portuguesa. Tanto a versão da narrativa recolhida por Sahusilawane (2008) como a de Christiaan (2011), em que o nome aparece, são contadas pelos falantes de meher. Como apontam Engelenhoven e Nazadurin (2016), o nome podia provir de fataluco e, de facto, não é um nome de pessoa, mas um topónimo (puna significando falésia). Alternativamente, Christiaan sugere que o nome é de origem javanesa, corrompido pelos falantes meher e/ou fataluco. Qualquer que seja a explicação correcta, o seu uso em várias narrativas é especialmente interessante visto que os povos locais recorrentemente usam nomes que indicam uma certa origem como marco identitário. Em tal contexto, essa aparente incongruência entre a etimologia do nome e a suposta origem da personagem parece significativa. Uma possível interpretação da recorrência de um nome de origem javanesa ou fataluco para o personagem português na tradição oral em Kisar é justamente a multiplicidade de influências culturais no contexto transnacional do Índico.

Essa história desempenha também uma outra função na topologia narratológica local. Como observado por Engelenhoven e Nazarudin (2016, p. 198), o kris dourado é um artefacto que permite introduzir um acontecimento histórico marcante na memória cultural da ilha. Segundo os relatos orais, a colonização holandesa de Kisar resultou dum pedido de auxílio militar do líder local à VOC para repelir uma tentativa de invasão portuguesa. Na memória popular, o kris surge como o casus beli para essa tentativa de invasão. Assim, a história do kris dourado, tanto ao nível micro como macronarrativo, revela como as identidades da matriz índica do Sudeste Asiático foram e continuam a ser formadas e renegociadas a partir de trânsitos e encontros que não podem ser circunscritos às atuais fronteiras nacionais. Construídas numa "poética de relação" (GLISSANT, 2010), são identidades intrinsecamente transnacionais, sendo que os traços, os "pedaços narrativos" desses trajetos seculares estão capturados nas tradições orais dos seus povos.

\section{AS LÍNGUAS, AS MIGRAÇÕES E A FORMAÇÃO DA NOVA NAÇÃO LESTE-TIMORENSE}

O cariz transnacional presente na narrativa do kris dourado da Ilha Kisar é também visível no imaginário nacional leste-timorense. As 
narrativas que podemos considerar fundacionais do nacionalismo de Timor-Leste reproduzem as características e as topologias das narrativas orais de carácter local, comoas referidas narrativas da ilha Kisar, e permitem uma abertura para outros espaços, outros trânsitos e outras heranças. Esse é o caso das narrativas orais que surgiram em torno da figura emblemática de Xanana Gusmão, o líder da luta pela independência e primeiro presidente de Timor-Leste, mostrando um movimento bidirecional entre o espaço nacional e o transnacional. Um exemplo desse tipo de narrativa é uma história contada por um informante do Porlamano - povoação no distrito Lautém -, que relata a história das várias vagas das migrações que influenciaram a paisagem linguística, a formação das identidades e finalmente o papel da sua comunidade na luta pela independência personificada por Xanana Gusmão.

A terra aqui em Porlamano é nossa. Tem muitos clãs com vários nomes mantendo relações complexas entre si que um estranho não pode compreender porque são baseadas em antigas histórias sagradas. Afinal, todos os outros são imigrantes que distinguimos em três categorias: a gente vinda do outro lado do mar de Banda que chegou com um barco ou um animal e que falava a nossa antiga língua macuva; a gente vinda a pé do oeste que chamamos samalai "donos da árvore Sá"13 que introduziram aqui a sua própria língua fataluco. Pois, os últimos foram os portugueses seguidos pelos bapak ${ }^{14}$ que trouxeram as suas próprias línguas.

Cada invasor tentou impor o seu pensamento, instalando a sua própria língua, porque a língua contém o conhecimento do povo. Somente os samalai falando o fataluco o conseguiram. Aqui não falamos português ou bahasa. ${ }^{15}$ mas os nossos antepassados adotaram o fataluco como uma língua mais completa que o macuva. Porque muita gente já não fala o macuva, muita gente não sabe bem ou não comprende mais a nossa verdadeira história.

O que quero dizer é que a sabemos todos, mas não temos noção que a sabemos. Quando os falantes de fataluco entraram na nossa terra, colocaram o seu fetulu ${ }^{16}$ em cima do pequeno símbolo da nossa mãe ancestral porque não o reconheceram. E por isso é que eles percebem

\footnotetext{
13 Neolamarckia catamba.

14 Palavra indonésia que significa "senhor", geralmente usada em Timor-Leste para indicar um militar indonésio.

${ }_{15}$ Palavra indonésia que significa "língua”, geralmente usada em Timor-Leste para indicar a língua indonésia.

16 Palavra fataluco que significa uma marca especial indicando a propriedade de um clã.
} 
que houve outros que os precederam sem saber quem eles eram. Eram os nossos antepassados.

Sabemos todos que Xanana é o nosso herói, o libertador da ocupação indonésia. Ele fala não só as línguas cooficiais tetum e português, mas também o galolen da sua região de nascimento, o bahasa e o inglês. Ele é um verdadeiro mestre de budi bahasa, ${ }^{17}$ mas o seu tokoh adat ${ }^{18}$ vem daqui. Muita gente já esqueceu que houve muitos libertadores antes de Xanana e haverá novos libertadores quando o momento deles precisar. O Xanana é a nossa criança. Nós escondemo-lo durante o funu. ${ }^{19}$ Quando ele foi procurado pelos bapak, nós carregámo-lo numa cesta de um lugar para outro.

O poder da nossa pátria está aqui. Nós falamos o fataluco - a verdadeira língua - que contém todo o conhecimento tradicional. Estamos a perdê-lo porque começámos a trocá-lo por português e tetum. O tetum é uma língua que tem que emprestar a palavra "janela” do português, porque não tem uma palavra própria. ${ }^{20}$ Esta língua é estranhamente igual ao fataluco.

$\mathrm{O}$ português é uma língua forte, mas feia. A gente do oeste considera-a boa, mas quando a ouvimos não conseguimos distinguir os vários significados. Também, quando está escrita, não conseguimos compreendê-la bem. O português usa sinais especiais nas suas letras para bloquear a nossa compreensão. O que significa esse pequeno verme sobre uma vogal ou esse anelzinho sob a letra c? São artifícios para esconder o verdadeiro significado das palavras nessa língua. Quando compreendermos o português, seremos capazes de obter todas as riquezas que estão afastadas de nós. Os portugueses estiveram em Timor quantos anos? Podemos compreender da sua língua que este povo é mais forte, mas não conseguiram ocupar a nossa terra aqui no leste.

A mesma coisa vemos com os bapak. Eles não conseguiram também. Mas eles não trouxeram a sua própria língua para aqui. O bahasa é a língua nacional de Indonésia, mas eu ouvi que os bapak são javaneses que têm uma outra língua que é mais complexa que o bahasa. $O$ bahasa é simples e não contém segredos. Os nossos poderes da terra têm mais força do que

17 Palavra indonésia que significa "virtuosismo linguístico".

18 Palavra indonésia que se traduz como "líder de tradição", significando o conselheiro principal em questões relacionadas à tradição.

19 Palavra tetum que significa "guerra", mas é geralmente usada para indicar a guerrilha contra os ocupantes indonésios.

20 O palestrante refere à palavra fataluco vaihula - “janela”. 
a que há no bahasa. Por isso preferimos comunicar nesta língua, e não em português, que é mais perigoso.

A introdução do português e do tetum é uma boa coisa. A força do português promete a entrada no mundo moderno, mas não é o nosso. O tetum é o nosso, mas é inferior ao fataluco. Eu prefiro-o ao bahasa porque é uma língua timorense. Uma vez terminado o meu tempo, o meu conhecimento e o dos meus pais desaparecerão. Somos como a palmeira de banana; depois de ter dado frutos tem que ser cortada. A introdução do português poderá aproximar as minhas crianças a um futuro melhor com os estrangeiros, mas afasta-los-á dos meus antepassados e de mim. $\mathrm{O}$ tetum é muito fraco para os manter. É a vida. Os jovens usam a frase "a luta continua" para se lembrar da nossa luta pela liberdade. Não compreendem que esta história continuará a repetir-se. Primeiro vieram os portugueses, depois os bapak. Hoje há as ONGs. A luta nunca acabará. ${ }^{21}$

Esse pequeno relato/conto ilustra a complexidade da ecologia linguística de Timor-Leste, onde as várias línguas estão relacionadas com diferentes domínios de expressão, mas também desempenham diferentes funções ao nível simbólico. A narrativa salienta que a introdução/ imposição de uma língua é crucial para que um povo possa ter qualquer influência na matriz social existente. $O$ território dos fataluco, e também todo o território nacional, é marcado por várias ondas de migrações, cujos traços mais visíveis são as línguas que ficaram. Nesse contexto, a comunidade constrói a sua identidade étnica a partir da língua fataluco, sendo que macuva, a única língua que pode dar acesso à "nossa verdadeira história” está prestes a desaparecer. No entanto, a sua identidade étnica, linguisticamente e territorialmente delimitada, não exclui a pertença a uma identidade nacional multicultural e multilíngue, marcada pelo ideal de budi bahasa e personificada por Xanana Gusmão.

"Muita gente já esqueci, houve muitos libertadores antes de Xanana e haverá novos libertadores quando o momento os precisará." Xanana, “o nosso herói", é aqui apresentado não como um guerillheiro e político que atuou numa época histórica específica, mas como um herói mítico (ou mitificado), uma das personagens grandes no panteão nacional. A nação precisa ser imaginada, simbólica e narrativamente construída, recorrendo à ideia de "comunidades imaginadas" de Anderson (1991). Nessa lógica, 
Xanana é transformado no imaginário popular de um homem em um mito. A mestria em diferentes línguas usadas no país não é aqui um simples valor para um político que assegurou a unidade nacional após a independência, mas um atributo simbólico que "comprova" o seu estatuto como herói. A ideia do nacionalismo leste-timorense que surge dessa narrativa parece apontar para um processo de constantes renegociações dos limites e fronteiras do corpo simbólico da nação. São as vagas de migrações vindas dos diferentes mares que contornam o seu território e que, ao longo da história, reformularam e continuam a reformular a identidade dos vários grupos étnicos; só um mestre de budi bahasa como Xanana - consegue assegurar uma identidade nacional no contexto das travessias transnacionais.

No entanto, esse grandioso herói não é apresentado como um ser inacessível e distante, mas pelo contrário como um membro próximo dessa comunidade; "é a nossa criança", como confessa a narradora pela voz feminina da contadora desta história, procedendo com a história de como Xanana foi escondido dos ocupantes indonésios pelos moradores de Porlamano. Seu esconderijo foi num cesto tradicional, usado exclusivamente pelas mulheres no Sudeste Asiático. A escolha de um cesto pode ser vista como uma estratégia bem pensada e bem sucedida, porque os homens indonésios, conscientes dos papéis de género envolvidos, não pensariam em procurar um chefe de guerrilha num objeto associado a mulheres. Porém a simbologia implícita em tal acontecimento leva a pensar em quem é o "nós" dessa narrativa nacional. Ao nível narrativo, Xanana (re)nasce do cesto, um atributo feminino, tornando-se "a nossa criança”, um afilhado e um pai protetor ao mesmo tempo. Contudo, o papel das mulheres na sua (temporária) salvação não é verbalizado, permanecendo apenas implícito na imagem do cesto/útero protetor. Assim, esse imaginário parece reiterar a representação das mulheres como mães da nação, mas a quem é renegada uma agência marcante na construção da mesma. É precisamente essa ambivalência que Anne McClintock (1993, p. 62) encontra como paradigmático nos chamados "nacionalismos masculinos", nos quais "gender difference between women and men serves to symbolically define the limits of national difference and power between men. Excluded from direct action as national citizens, 
women are subsumed symbolically into the national body politic as its boundary and metaphoric limit".22

\section{TIMOR-LESTE E O ÍNDICO - CONSIDERAÇÕES FINAIS}

O Índico como espaço simbólico não parece ser um motivo proeminente nas narrativas orais transmitidas de geração a geração entre os povos de Timor-Leste. As suas águas são frequentemente cobertas por um véu de silêncio. No entanto, o estudo da tradição oral no país em particular e na região do Sudeste Asiático em geral pode revelar "pedaços narrativos", fragmentos de memórias e histórias que apontam para a rica rede de contactos transnacionais que caracterizavam o Índico, visto como um sítio de "modernidades alternativas" (cf. HOFMEYR, 2007) ainda não plenamente exploradas. Mais especificamente no contexto da presença portuguesa nesses mares, as tradições orais confrontam os pesquisadores com problemas e desafios de ordem metodológica que põem em questão os universalismos construídos a partir de fatores histórica e politicamente determinados. Que línguas e que nações incluir no corpus de análise num projecto que pretende estudar de forma crítica o Índico "lusófono"? Essa é uma questão de fundo, e o estudo da tradição oral obriga a repensar as categorias de pertença e exclusão que determinam o próprio conceito de lusofonia.

\section{SOUTHEAST ASIA AND THE INDIAN OCEAN: REFLECTIONS ON LINGUISTIC AND CULTURAL TRANSITS IN ORAL TRADITIONS IN EAST TIMOR}

Abstract: Although some Southeast Asian religions, writing systems, elements of mythologies and important vocabulary were adopted as result of intercultural contacts established in the Indian Ocean, this region has received little attention in the field of Indian Ocean Studies (REID, 2007). In order to fill in this gap and contribute to a better understanding of the cultural and identity geography of the Indian Ocean, seen as a transnational space, this article proposes to study oral traditions in East Timor as a methodological tool to study the memory (and oblivion) of the cultural transits that influenced the formation of this Portuguese-speaking country. The analysis of oral

22 "[...] a diferença de género entre mulheres e homens serve para definir simbolicamente os limites da diferença nacional e do poder entre pessoas. Excluídas da acção directa como cidadãs nacionais, as mulheres são agrupadas simbolicamente na política nacional como a sua fronteira e limite metafórico". 
narratives from East Timor and neighbouring West Maluku reveals how the operational categories of "language" and "nation" are problematic in such a transnational context as the Indian Ocean. In the context of the Portuguese presence, oral traditions present researchers with methodological problems and challenges which question universalisms formed out of historically and politically determined factors.

Keywords: East Timor; Indian Ocean; oral traditions.

\section{REFERÊNCIAS}

ANDERSON, Benedict. Imagined Communities: Reflections on the Origin and Spread of Nationalism. Londres: Verso, 1991.

CHAMBERS, Iain. Power, Language and the Poetics of the Postcolonial. In: LEITE, Ana Mafalda et al. (Eds.). Narrating the Postcolonial Nation: Mapping Angola and Mozambique. Oxford: Peter Lang, 2014, pp. 5-14.

CHRISTIAAN, Hendrik Natalus Sejarah suku Mauko'o di pulau Kisar. Christiaan Maukoo's Blog, 2011. Disponível em: <https://christiaanmaukoo.wordpress.com/2011/o8/o8/ sejarah-suku-mauko\%E2\%8o\%99o-di-pulau-kisar/>. Acesso em: 1 dez. 2017.

ENGELENHOVEN, Aone van. Living the Never-Ending Story: On Story-Telling in Tutuala (East Timor) and Southwest Maluku (Indonesia). In: CASTRO SEIXAS, Paulo (Ed.). Translation, Society and Politics in Timor-Leste. Porto: Fernando Pessoa University Press, 2010, pp. 61-76.

ENGELENHOVEN, Aone van. Observações sobre narrações orais em Tutuala (TimorLeste) e no sudoeste das Molucas (Indonésia). In: SILVA, K.; SOUSA, L. (Eds.). Ita Maun Alin... O livro do irmão mais novo. Afinidades antropológicas em torno de Timor-Leste. Lisboa: Edições Colibri, 2012, pp. 133-153.

ENGELENHOVEN, Aone van. The Spoor of the Mythical Sailfish; Narrative Topology and Narrative Srtefacts in Southwest Maluku (Indonesia) and Tutuala (East Timor). In: REVEL-MACDONALD, Nicole (Ed.). Songs of Memory in Islands of Southeast Asia. Newcastle upon Tyme: Cambridge Scholars Publishing, 2013, pp. 251-286.

ENGELENHOVEN, Aone van. Petjoh: "Indisch" Nederlands of Nederlands Maleis, Feit of Fictie? Praagse perspectieven, v. 9, 2014, pp. 45-65.

ENGELENHOVEN, Aone van. Teaching Indonesian in Europe: Clashes between Language folklore and Language Ideology. Comunicação apresentada no lançamento do Language Learning Centre da Leiden University, 2017. (Mimeo.)

ENGELENHOVEN, Aone van; NAZARUDIN. A Tale of Narrative Annexation. Stories from Kisar Island (Southwest Maluku, Indonesia). Wacana, v. 17, n. 2, 2016, pp. 191-231.

FALCONI, Jessica. Literaturas Africanas, língua portuguesa e narrativas da Lusofonia: alguns parágrafos em torno da invenção das narrativas da "lusofonia”. In: LEITE, Ana 
O sudeste asiático e o Índico... - 238

Mafalda et al. (Ed.). Nação e narrativa pós-colonial I, Angola e Moçambique: ensaios. Lisboa: Colibri, 2012.

FINNEGAN, Ruth. Oral Tradition and the Verbal Arts. Londres/Nova York: Routledge, 1992.

GEJIN, Chao. Mongolian Oral Epic Poetry: An Overview. Oral Tradition, v. 12, n. 2, 1997, pp. 322-336.

GLISSANT, Édouard. Poetics of Relation. Ann Arbor: University of Michigan Press, 2010.

GOGLIA, Francesco; Susana, AFONSO. Multilingualism and Language Maintenance in the East Timorese Diaspora in Portugal. Ellipsis, v. 10, 2012, pp. 73-99.

GOMES, Nuno da Silva. A literatura popular de tradição oral em Timor-Leste. Tese (Mestrado em Educação) - Universidade de Minho. Braga, 2007.

HOFMEYR, Isabel. The Black Atlantic Meets the Indian Ocean: Forging New Paradigms of Transnationalism for the Global South - Literary and Cultural Perspectives. Social Dynamics: A Journal of African Studies, v. 33, n. 2, 2007, pp. 3-32.

HOFMEYR, Isabel. Universalizing the Indian Ocean. PLMA, v. 125, n. 3, 2010, pp. 721-729.

LEAL DE BARROS, Anabela. Contos e lendas de Timor-Leste. VN Famalicão: Húmus, 2015.

LEAL DE BARROS, Anabela. Rumando de Lés a Leste: contos e lendas de Oecusse. VN Famalicão: Húmus, 2017.

MCCLINTOCK, Anne. Family Feuds: Gender, Nationalism and the Family. Feminist Review (Special Issue Nationalisms and National Identities), v. 44, 1993, pp. 61-80.

MEROLLA, Daniela. Reflections on the Project: "African Oral Literatures, New Media, and Technologies: Challenges for Research and Documentation”. The Global South, v. 5, n. 2, 2012, pp. 154-162.

MOUTINHO, Isabel. Historicity and Storytelling in East Timorese Fiction in Portuguese. Ellipsis, v. 10, 2012, pp. 101-122.

PAULINO, Vicente. Writing and Translating Timorese Oral Tradition. Configurações, v. 17, 2016, pp. 79-98.

PEARSON, Michael. The Indian Ocean. Oxon: Routledge, 2003.

REID, Anthony. Aceh between Two Worlds: An Intersection of Southeast Asia and the Indian Ocean. In: RAY, Himanshu P.; Edward Alpers (Eds.). Cross Currents and Community Networks: The History of the Indian Ocean World. Nova Delhi: Nehru Memorial Museum and Library / OUP, 2007, pp. 100-132. 
Remate de Males, Campinas-SP, v. 38, n. 1, pp. 220-239, jan./jun. 2018 - 239

REINWARDT, Caspar Georg Carl; VRIESE, Willem Hendrik. Reis naar het oostelijk gedeelte van den Indischen Archipel in het jaar 1821. Amsterdam: Frederik Muller, 1858.

RIEDEL, Johann Gerard Friedrich. Het Eiland Keisar of Mekisar, De sluik- en kroesharige rassen tusschen Selebes en Papua: Uitgegeven door tuschenkomst van het Nederlandsch-aardrijkskundig genootschap. M. Nijhoff: The Hague, 1886.

RODENWALDT, Ernst. Die Mestizen aufKisar Band I. Mit einem Beitrage von K. Saller ueber "Mikroskopische Beobachtungen an den Haaren der Kisaresen und Kisarbastarde". 2 vols., Mededeelingen van den Dienst der Volksgezondheid in Nederlandsch-Indie. G. Fischer: Jena, 1928.

SAHUSILAWANE, Florence. 20o8. Sejarah Kerajaan Kisar. In: SAHUSILAWANE, Florence. (Ed.). Jurnal Penelitian; Seri penerbitan sejarah dan budaya. Ambon: Departemen Kebudayaan dan Pariwisata, Balai Pelestarian Sejarah dan Nilai Tradisional Provinsi Maluku dan Maluku Utara, 2008, pp. 1-6o.

SWEENEY, Amin. A Full Hearing: Orality and literacy in the Malay world. Berkeley, CA: University of California Press, 1987.

TAYLOR-LEECH, Kerry. Language and Identity in East Timor. The Discourses of Nation Building. Language Problems and Language Planning, v. 32, n. 2, 2008, pp. 153-180.

TEDLOCK, Dennis. The Spoken Word and the Work of Interpretation. Filadélfia: University of Pennsylvania Press, 1983.

VANSINA, Jan. Oral Tradition as History. Madison, WI: University of Wisconsin Press, 1985.

VERTOVEC, Steven. Conceiving and Researching Transnationalism. Ethnic and Racial Studies, v. 22, n. 2, 1999, pp. 447-462. 